\title{
Association between Degrees of Malnutrition and Clinical Outcomes among Non-critically III Hospitalized Adult Patients with Type 2 Diabetes Mellitus*
}

\author{
Freyja Diana Ramos, ${ }^{1}$ Joy Arabelle Fontanilla,,${ }^{1,2}$ Reginna Emiliene Lat ${ }^{2}$ \\ ${ }^{1}$ Center for Diabetes, Thyroid and Endocrine Disorders, St. Luke's Medical Center, Global City, Taguig, Philippines \\ ${ }^{2}$ Center for Weight Intervention and Nutrition Services, St. Luke's Medical Center, Global City, Taguig, Philippines
}

\begin{abstract}
Introduction. Malnutrition among hospitalized patients is highly prevalent. This adversely affects outcomes with longer length of stay (LOS), higher treatment costs and increased mortality. People with diabetes mellitus (DM) are particularly vulnerable to malnutrition and its consequences.
\end{abstract}

Objective. To determine the association of nutritional status with LOS and mortality among adults with Type 2 DM.

Methodology. This was a retrospective study of 439 adult patients with type 2 diabetes admitted in the medical ward of a tertiary hospital from January 1, 2018 to December 31, 2018. Demographics, anthropometrics, feeding route, LOS and outcomes were taken from the Clinical Nutrition Service database; biochemical data were taken from the Healthcare System, and were analyzed.

Results. In our analysis, $83.8 \%$ were found to be malnourished with $50.3 \%$ moderately-malnourished (MM) (Nutrition risk level 1-2) and 33.5\% severely-malnourished (SM) (Nutrition risk level $\geq 3$ ). BMI category and malnutrition were the significant confounders for LOS. After controlling for BMI, LOS was longer by a mean of 2.2 days in SM compared to well-nourished (WN) patients $(95 \% \mathrm{Cl}=0.49-3.95, p=0.012)$. Of the malnourished patients, $6.1 \%$ of $\mathrm{SM}$ and $0.5 \%$ of MM patients died. None of the WN patients died. Feeding route, admitted for neoplasm, low albumin levels and malnutrition were the confounding factors associated with mortality. After controlling for these factors, SM had higher odds of dying compared to MM patients [adjusted $\mathrm{OR}=8.91(95 \% \mathrm{Cl}=1.04-76.18, p=0.046)$ ].

Conclusion. Among hospitalized non-critically ill adult patients with type 2 diabetes, SM patients but not MM patients had significantly longer LOS compared to WN patients, and greater degrees of malnutrition were associated with higher mortality.

Key words: malnutrition, hospital outcome, diabetes mellitus

\section{INTRODUCTION}

Malnutrition, as defined by the World Health Organization (WHO), refers to deficiencies, excesses or imbalances in a person's intake of energy and/or nutrients. ${ }^{1}$ It is classified into undernutrition, which include stunting, wasting, underweight and micronutrient deficiencies or insufficiencies; and overweight, obesity and diet-related non-communicable diseases such as heart disease, stroke, diabetes and cancer. Using current WHO BMI guidelines, it is usually associated with a body mass index (BMI) of less than $18.5 \mathrm{~kg} / \mathrm{m}^{2}$ (underweight) or $30 \mathrm{~kg} / \mathrm{m}^{2}$ and above (obese). ${ }^{2}$

Hospitalized patients, regardless of their BMI, typically suffer from undernutrition because of reduced food intake due to illness-induced poor appetite, gastrointestinal symptoms, reduced ability to chew or swallow, or nil per-os status for diagnostic and therapeutic procedures. ${ }^{3}$ Malnutrition is a debilitating and highly prevalent condition in the acute hospital setting. It is estimated that at least onethird of patients have some degree of malnutrition upon admission to the hospital. If left untreated, approximately two thirds of these patients will experience a further decline in their nutritional status during in-patient stay. ${ }^{4}$ Its prevalence in the hospital setting has been widely documented in the literature to be between $20 \%$ to $50 \%{ }^{5}$

In the Philippine setting, the prevalence of malnutrition among hospitalized patients is between 48 to $53 \%$. With these data, it is concluded that every hospital in the Philippines has malnourished patients. ${ }^{6}$ Patients with
ISSN 0857-1074 (Print) | eISSN 2308-118x (Online)

Printed in the Philippines

Copyright $(\odot) 2021$ by Ramos et al.

Received: February 22, 2021. Accepted: July 29, 2021.

Published online first: August 20, 2021

https://doi.org/10.15605/jafes.036.02.12
Corresponding author: Freyja Diana A. Ramos, MD

Fellow, St. Luke's Medical Center - Global City

Rizal Drive corner $32^{\text {th }}$ Street and $5^{\text {th }}$ Avenue,

Taguig City, 1634 Metro Manila

Tel. No.:8-789-7700 local 2086

E-mail:freyjadiana@yahoo.com

ORCiD: https://orcid.org/0000-0001-8395-3293

\footnotetext{
* This paper was presented in the Philippine Society for Parenteral and Enteral Nutrition (PhilSPEN) Annual Convention, Mandaluyong City, Philippines, November 25, 2019 and placed second during the oral presentations.
} 
diabetes mellitus are susceptible to malnutrition due to disease complications such as poor dentition, eating disorders, alterations in bowel movement or gastroparesis and cognitive disorders. Malnutrition in patients with diabetes was highly prevalent in the acute hospital setting, in which $37 \%$ had moderate risk, and $63 \%$ had high risk for malnutrition. Fifty-five percent of patients had mild to moderate malnutrition, and $45 \%$ of patients had severe malnutrition. ${ }^{7}$

An average of $10 \%$ loss of lean body mass results in immune suppression and increases the risk of infection, $15 \%$ to $20 \%$ loss will impair wound healing, and a 30\% loss leads to the development of spontaneous wounds, such as pressure ulcers, an increased risk of pneumonia, and a complete lack of wound healing. ${ }^{4}$ Malnutrition is associated with many adverse outcomes including depression of the immune system, impaired wound healing, muscle wasting, longer lengths of hospital stay, higher treatment costs and increased mortality. ${ }^{8}$

Patients who were admitted with some degree of malnutrition, and those patients who experienced a decline in nutritional status during their admission, had significantly longer hospital stay by an average of 4 days than patients both admitted and discharged as wellnourished. ${ }^{9}$

Due to the high prevalence of malnutrition and adverse outcomes in the hospital setting, every patient admitted should be screened for malnutrition risk. Nutrition Risk Screening (NRS) is the first step in identifying patients at risk for malnutrition. It uses recent weight loss, BMI and reduced dietary intake, combined with a subjective assessment of disease severity. Such subjective grading of illness severity may not accurately reflect current nutritional status and this tool does not allow for definitive diagnosis of malnutrition. However, it has been recommended for use in hospitalized patients and may be useful for prompting the initiation of nutrition support. ${ }^{10}$ Patients who were screened to be nutritionally at-risk are further evaluated using nutritional assessment tool/s to label and classify malnourished patients.

Subjective Global Assessment (SGA) is a tool used to confirm the result of NRS. There are five questions focusing on history of unintentional weight loss over the past six months, dietary intake change, gastrointestinal symptoms of more than 2 weeks, functional capacity and metabolic demands of the underlying condition. Physical examination explores muscle, fat mass, and the existence of edema. Each feature is noted as normal, mild, moderate, or severe according to clinician's subjective impression. The nutritional status is classified as well-nourished, moderately-malnourished, or severely-malnourished. ${ }^{5}$

Malnutrition was prevalent on admission and discharge, and malnourished patients were older, suffered more serious disease, had comorbidities, and had longer hospital stay and higher risk of mortality. ${ }^{9}$ Particularly among patients with diabetes, the factors associated with high nutritional risk for malnutrition were abnormal BMI, lower albumin, and lower total lymphocyte count (TLC). ${ }^{7}$
It is not clear what level of malnutrition is associated with poor hospital outcome specifically in patients with diabetes in the local setting. We studied the association of degrees of malnutrition and hospital outcomes in terms of length of stay and mortality among hospitalized patients with diabetes in the medical ward of a tertiary institution. In addition, we analyzed confounding factors affecting nutritional status in these patients and correlated them to the degrees of malnutrition.

\section{Definition of terms}

A. Nutritionally at risk is defined based on the NRS tool, with at least one of the following three criteria:

1. $\mathrm{BMI}<18.5 \mathrm{~kg} / \mathrm{m}^{2}$ or $\geq 30 \mathrm{~kg} / \mathrm{m}^{2}$

2. Weight loss within the last 3 months

3. Severely ill, i.e., head injury, cancer, Intensive Care Unit (ICU) patients, sepsis, burns ( $>50$ total body surface area or TBSA), bone marrow or solid transplantation, severe acute pancreatitis, patients on regular hemodialysis or peritoneal dialysis

B. Well-nourished or normal is a nutritional status defined by a nutritional risk level score of zero (Appendix).

C. Moderately-malnourished or moderate malnutrition is a nutritional status defined by a nutritional risk level score of 1 to 2 .

D. Severely-malnourished or severe malnutrition is a nutritional status defined by a nutritional risk level of 3 and above.

\section{Objective}

To determine the association of nutritional status with length of hospital stay and mortality among adult patients with type 2 diabetes mellitus.

\section{METHODOLOGY}

\section{Patients}

This study included non-critically ill adult patients with type 2 diabetes mellitus aged 19 years and above, admitted for at least 24-hours in the medical ward. We excluded patients initially admitted in the intensive care unit (ICU) within the first 24-hours, patients admitted for executive check-up or chemotherapy, pregnant and surgical patients, and type $1 \mathrm{DM}$. This study was approved by the Institutional Ethics and Review Board with reference number CT-18251 on 21 February 2019.

\section{Design}

This was a retrospective analytical study that involved patients admitted in the medical ward of St. Luke's Medical Center - Global City in Taguig City, Philippines from January 1, 2018 to December 31, 2018. All patients admitted in the hospital were screened for nutrition risk by the nurse-on-duty using the NRS. Patients who were found to be nutritionally at risk on admission were assessed by the Clinical Nutrition Service (CNS) to determine their nutritional status (Appendix). Patients' nutritional status are then recorded in the database of the CNS. Eligible subjects were selected from this database.

Nine hundred forty-five patients were eligible for the study. Out of the 945 patients, 506 had incomplete laboratory results including one with type 1 diabetes and were thus excluded. A total of 439 patients were included in the study. The data collected from the CNS database were the 
age, sex, diagnosis/reason for admission, co-morbidities, anthropometric measurements, route of feeding, NRS, SGA, LOS, and hospital outcomes (discharged or deceased). The white blood cell (WBC) count, glycosylated hemoglobin $(\mathrm{HbA} 1 \mathrm{c})$, and serum albumin of these patients were taken from the Healthcare System record of the hospital. The total lymphocyte count was calculated using the formula TLC $=$ WBC $\times$ lymphocyte count $\%$.

\section{Sample size estimation}

Sample size was calculated based on the comparison of the length of hospital stay among severely malnourished and well-nourished patients. Assuming that mean length of hospital stay among severely malnourished patients is $5.1 \pm 4.9$ SD days and for well-nourished patients, $2.9 \pm 1.9$ SD days, ${ }^{7}$ with an alpha error of $5 \%$, power of $95 \%$ and onetailed alternative hypothesis, sample size calculated is 62 per group or 186 for three groups. Controlling for 4 more variables in the analysis, with an additional $20 \%$ for each control variable, final sample size required is 336 .

\section{Data analysis}

Descriptive statistics was done using the mean and standard deviation for quantitative variables and frequencies and proportions for categorical variables.

Determination of the association between nutritional status and length of hospital stay was analyzed using univariate and multivariate statistics. ANOVA/t-test and linear regression were used for categorical and continuous independent variables, respectively, in the univariate analysis. Multiple linear regression was then utilized in the multivariate analysis using forward elimination.

Determination of the association of nutritional status and mortality was also analyzed using univariate and multivariate statistics. Malnutrition status was categorized as severely and moderately-malnourished in the analyses. Chi-square test and logistic regression for categorical and continuous independent variables, respectively were done in the univariate analysis. Crude odds ratio and the $95 \%$ confidence interval were also calculated. Multiple logistic regression was then utilized in the multivariate statistics using backward elimination.

To control for confounders, different demographic and clinical profiles were tested for their association with nutritional status in the univariate analysis using Chisquare test and ANOVA/t-test. Variables with p-value less than 0.30 were included in the multivariate analysis.

Analysis was done using Stata v.14. P-value less than 0.05 was considered significant.

\section{RESULTS}

Four hundred thirty-nine patients were included in the study, of whom $61.5 \%$ were males. The mean age was 67.4 years and mean BMI was $28.2 \mathrm{~kg} / \mathrm{m}^{2}$. Only $5.9 \%$ of the patients were fed via enteral tube feeding (nasogastric tube or gastrostomy tube), and the rest were fed per orem. The most common reason for admission was pneumonia/ respiratory insufficiency $(20.7 \%)$. Most $(96.1 \%)$ of the patients had co-morbidities with cardiovascular $(72.2 \%)$ being the most common (Table 1).
The prevalence of malnutrition among the 439 hospitalized patients with type 2 diabetes in the study was $83.8 \%$. The proportion of moderately-malnourished and severelymalnourished patients were $50.3 \%$ and $33.5 \%$, respectively. Older mean age was observed as the degrees of malnutrition increased. In terms of BMI, most of the patients were normal and obese I (both $27.3 \%$ ), and a few were obese III $(4.3 \%)$. Enteral tube route of feeding was noted in the malnourished group and none in the well-nourished group (Table 1). Among the variables, age group, BMI category, feeding route, metabolic derangement and neoplasm (as reasons for admission), and presence of co-morbidities (specifically cancer and lung disease) were the confounders of nutritional status $(p<0.05)$.

Overall, the average LOS of patients was 6.7 days. Pairwise comparison showed that severely-malnourished patients had significantly longer LOS than patients who were moderately-malnourished and well-nourished. Furthermore, moderately-malnourished patients had significantly longer LOS than well-nourished patients (Table 2$)$. Ten $(2.3 \%)$ patients died as observed in the study. The proportion of deceased patients is also significantly different among the 3 groups: $9(6.1 \%)$ patients and $1(0.5 \%)$ patient died from the groups of severely-malnourished and moderately-malnourished patients, respectively. No deaths occurred in the group of well-nourished patients (Table 2).

Body mass index (BMI) and malnutrition were the factors significantly affecting length of stay. Holding nutritional status constant, for every one unit increase in BMI, the LOS decreased on the average by 0.2 day, or for every 5 units increase in BMI, the LOS decreased on the average by 1 day. Holding BMI constant, LOS increased on the average by about 2.2 days in severely-malnourished patients compared to well-nourished patients (Table 3).

In the univariate analysis, feeding route, admission for neoplasm, low albumin levels, and malnutrition were significantly associated with mortality. The odds of dying among patients on oral feeding were 0.13 or $87 \%$ less likely than patients on enteral tube feeding. Patients admitted for neoplasm had more than 4 times the odds of dying compared to those who were not admitted for this reason (Table 4 ).

Other reasons for admission were ear, throat and systemic infections, veno-occlusive disease, syncope, hypersensitivity reaction, neurodegenerative disorders and hematologic conditions.

The following reasons for admission had relative risks (RR) to be discharged alive: urinary tract infection $[R R=1.02$ (95\% CI=1.01-1.04, $p=0.496)]$, acute gastrointestinal disease [RR=1.03 (95\% CI=1.01-1.04, $p=0.262)]$, cerebrovascular disease $\quad[R R=1.02 \quad(95 \% \quad C I=1.01-1.04, p=0.592)]$, skin infections $[R R=1.02(95 \% \quad C I=1.01-1.04, p=0.534)]$, acute musculoskeletal disease $[\mathrm{RR}=1.02 \quad(95 \% \quad \mathrm{CI}=1.01-1.04$, $p=0.562)]$, and others [RR=1.03 (95\% CI=1.01-1.04, $p=0.362)]$.

The following co-morbidities had relative risks to be discharged alive: genitourinary $[\mathrm{RR}=1.02$ (95\% CI=1.011.04, $p=0.576)]$, endometabolic $[R R=1.03(95 \% \mathrm{CI}=1.01-1.04$, $p=0.257)]$, neurologic [RR=1.03 (95\% CI=1.01-1.04, $p=0.268)]$, 
Table 1. Baseline demographics and clinical profile of patients

\begin{tabular}{|c|c|c|c|c|c|}
\hline & $\begin{array}{c}\text { Well-nourished } \\
n=71(16.2 \%)\end{array}$ & $\begin{array}{c}\text { Moderately-malnourished } \\
n=221(50.3 \%)\end{array}$ & $\begin{array}{c}\text { Severely-malnourished } \\
n=147(33.5 \%)\end{array}$ & $\begin{array}{l}\text { Overall } \\
n=439\end{array}$ & $p$-value \\
\hline Age, mean years \pm SD & $55.9 \pm 15.14$ & $69.0 \pm 12.70$ & $70.6 \pm 13.42$ & $67.4 \pm 14.27$ & $<0.001^{* *}$ \\
\hline Age groups (years), n (\%) & & & & & $<0.001$ \\
\hline Young adult (19-35) & $6(8.5)$ & $3(1.4)$ & $1(0.7)$ & $10(2.3)$ & \\
\hline Middle aged (36-55) & $25(35.2)$ & $28(12.7)$ & $23(15.6)$ & $76(17.3)$ & \\
\hline Older adult (56-64) & $20(28.2)$ & $43(19.5)$ & $23(15.6)$ & $86(19.6)$ & \\
\hline Young elderly (65-74) & $7(9.9)$ & $79(35.7)$ & $70(47.6)$ & $156(35.5)$ & \\
\hline Old elderly $(\geq 75)$ & $13(18.3)$ & $68(30.8)$ & $30(20.4)$ & $111(25.3)$ & \\
\hline Sex, n (\%) & & & & & 0.161 \\
\hline Male & $50(70.4)$ & $128(57.9)$ & $92(62.6)$ & $270(61.5)$ & \\
\hline Female & $21(29.6)$ & $93(42.1)$ & $55(37.4)$ & $169(38.5)$ & \\
\hline $\mathrm{BMI}$, mean $\mathrm{kg} / \mathrm{m}^{2} \pm \mathrm{SD}$ & $33.6 \pm 5.23$ & $27.4 \pm 6.10$ & $26.8 \pm 6.78$ & $28.2 \pm 6.63$ & $<0.001^{* *}$ \\
\hline \multicolumn{6}{|l|}{ BMI class $\left(\mathrm{kg} / \mathrm{m}^{2}\right), \mathrm{n}(\%)$} \\
\hline Normal $(18.5-<25)$ & $3(4.2)$ & $69(31.2)$ & $48(32.7)$ & $120(27.3)$ & $<0.001$ \\
\hline Underweight $(<18.5)$ & $0(0.0)$ & $9(4.1)$ & $14(9.5)$ & $23(5.2)$ & \\
\hline Overweight $(25-<30)$ & $8(11.3)$ & $71(32.1)$ & $35(23.8)$ & $114(26.0)$ & \\
\hline Obese I $(30-<35)$ & $36(50.7)$ & $51(23.1)$ & $33(22.4)$ & $120(27.3)$ & \\
\hline Obese II $(35-<40)$ & $20(28.2)$ & $10(4.5)$ & $13(8.8)$ & $43(9.8)$ & \\
\hline Obese III $(\geq 40)$ & $4(5.6)$ & $11(5.0)$ & $4(2.7)$ & $19(4.3)$ & \\
\hline Feeding route, $\mathrm{n}(\%)$ & & & & & $<0.001$ \\
\hline Oral & $71(100.0)$ & $217(98.2)$ & $125(85.0)$ & $413(94.1)$ & \\
\hline Enteral tube & $0(0.0)$ & $4(1.8)$ & $22(15.0)$ & $26(5.9)$ & \\
\hline \multicolumn{6}{|l|}{ Reasons for admission, $\mathrm{n}(\%)$} \\
\hline AKI/insufficiency & $5(7.0)$ & $21(9.5)$ & $17(11.6)$ & $43(9.8)$ & 0.562 \\
\hline Pneumonia/respiratory insufficiency & $12(16.9)$ & $44(19.9)$ & $35(23.8)$ & $91(20.7)$ & 0.456 \\
\hline UTI & $5(7.0)$ & $8(3.6)$ & $6(4.1)$ & $19(4.3)$ & 0.460 \\
\hline Acute GI disease & $10(14.1)$ & $22(10.0)$ & $16(10.9)$ & $48(10.9)$ & 0.624 \\
\hline CVD & $0(0.0)$ & $7(3.2)$ & $5(3.4)$ & $12(2.7)$ & 0.301 \\
\hline Metabolic derangement & $11(15.5)$ & $12(5.4)$ & $11(7.5)$ & $34(7.7)$ & 0.022 \\
\hline CAD & $6(8.5)$ & $18(8.1)$ & $9(6.1)$ & $33(7.5)$ & 0.731 \\
\hline HTN/heart failure & $9(12.7)$ & $15(6.8)$ & $10(6.8)$ & $34(7.7)$ & 0.237 \\
\hline Skin infection & $3(4.2)$ & $5(2.3)$ & $8(5.4)$ & $16(3.6)$ & 0.269 \\
\hline Neoplasm & $2(2.8)$ & $49(22.2)$ & $14(9.5)$ & $65(14.8)$ & $<0.001$ \\
\hline Acute MS disease & $3(4.2)$ & $7(3.2)$ & $4(2.7)$ & $14(3.2)$ & 0.839 \\
\hline Others & $5(7.0)$ & $14(6.3)$ & $14(9.5)$ & $33(7.5)$ & 0.517 \\
\hline \multicolumn{6}{|l|}{ Comorbidities, n (\%) } \\
\hline Without comorbidities & $8(11.3)$ & $6(2.7)$ & $3(2.0)$ & $17(3.9)$ & 0.002 \\
\hline With comorbidities & $63(88.7)$ & $215(97.3)$ & $144(98.0)$ & $422(96.1)$ & \\
\hline Cancer & $2(2.8)$ & $85(38.5)$ & $35(23.8)$ & $122(27.8)$ & $<0.001$ \\
\hline Cardiovascular & $47(66.2)$ & $166(75.1)$ & $104(70.7)$ & $317(72.2)$ & 0.307 \\
\hline Lung disease & $5(7.0)$ & $22(10.0)$ & $25(17.0)$ & $52(11.8)$ & 0.048 \\
\hline Gastrointestinal & $1(1.4)$ & $15(6.8)$ & $10(6.8)$ & $26(5.9)$ & 0.213 \\
\hline Kidney disease & $18(25.4)$ & $79(35.7)$ & $61(41.5)$ & $158(36.0)$ & 0.066 \\
\hline Genitourinary & $3(4.2)$ & $6(2.7)$ & $4(2.7)$ & $13(3.0)$ & 0.790 \\
\hline Endometabolic & $12(16.9)$ & $22(10.0)$ & $15(10.2)$ & $49(11.2)$ & 0.244 \\
\hline Neurologic & $5(7.0)$ & $21(9.5)$ & $21(14.3)$ & $47(10.7)$ & 0.192 \\
\hline Rheumatologic & $2(2.8)$ & $2(0.9)$ & $6(4.1)$ & $10(2.3)$ & 0.128 \\
\hline Hematologic & $1(1.4)$ & $3(1.4)$ & $0(0.0)$ & $4(0.9)$ & 0.362 \\
\hline Dermatologic & $0(0.0)$ & $1(0.5)$ & $0(0.0)$ & $1(0.2)$ & 0.610 \\
\hline Total lymphocyte count, mean $\mathrm{mm}^{3} \pm \mathrm{SD}$ & $2045.3 \pm 839.09$ & $1761.7 \pm 1602.49$ & $1889.7 \pm 4356.06$ & $1850.4 \pm 2781.74$ & $0.741^{* *}$ \\
\hline Albumin, mean g/dL \pm SD & $3.8 \pm 3.69$ & $3.1 \pm 0.71$ & $2.8 \pm 0.67$ & $3.1 \pm 1.64$ & $<0.001^{* *}$ \\
\hline $\mathrm{HbA} 1 \mathrm{c}$, mean $\% \pm \mathrm{SD}$ & $8.3 \pm 2.25$ & $7.2 \pm 1.56$ & $7.1 \pm 1.65$ & $7.3 \pm 1.76$ & $<0.001^{* *}$ \\
\hline
\end{tabular}

Table 2. Length of stay and number of patients deceased according to nutritional status

\begin{tabular}{|c|c|c|c|c|c|}
\hline & $\begin{array}{c}\text { Well-nourished } \\
n=71(16.2 \%)\end{array}$ & $\begin{array}{l}\text { Moderately-malnourished } \\
n=221(50.3 \%)\end{array}$ & $\begin{array}{c}\text { Severely-malnourished } \\
n=147(33.5 \%)\end{array}$ & $\begin{array}{c}\text { Overall } \\
n=439\end{array}$ & $p$-value \\
\hline LOS, mean days \pm SD & $4.1 \pm 3.55$ & $6.5 \pm 6.03$ & $8.3 \pm 8.14$ & $6.7 \pm 6.66$ & $<0.001^{*}$ \\
\hline Deceased, n (\%) & $0(0.0)$ & $1(0.5)$ & $9(6.1)$ & $10(2.3)$ & $0.001^{* *}$ \\
\hline
\end{tabular}

Table 3. Multivariate analysis of the association between factors and length of stay (number of days)

\begin{tabular}{llr}
\hline & $\begin{array}{c}\text { Beta Coefficients } \\
(\mathbf{9 5 \%} \mathbf{C l})\end{array}$ & $\boldsymbol{p}$-value \\
\hline Body mass index & $-0.2(-0.29--0.10)$ & $<0.001$ \\
Normal vs severely-malnourished & $2.2(0.49-3.95)$ & 0.012 \\
Normal vs moderately-malnourished & $1.2(-0.40-2.74)$ & 0.142 \\
\hline & &
\end{tabular}

rheumatologic $\quad[\mathrm{RR}=1.02 \quad(95 \% \quad \mathrm{CI}=1.01-1.04, \quad p=0.625)]$, hematologic $\quad[R R=1.02 \quad(95 \% \quad C I=1.01-1.04, \quad p=0.759)]$, dermatologic [RR=1.02 (95\% CI=1.01-1.04, $p=0.879)]$.

For every one unit increase in albumin, the odds of dying decreased by $63 \%$. No mortality was recorded in the wellnourished group, hence only malnourished groups were analyzed. Severely-malnourished patients had more than 14 times the odds of dying compared to moderatelymalnourished patients (Table 4). In the multivariate analysis 


\begin{tabular}{|c|c|c|}
\hline & $\begin{array}{l}\text { Unadjusted Odds } \\
\text { Ratio (CI 95\%) }\end{array}$ & $p$-value \\
\hline \multicolumn{3}{|l|}{ Age group } \\
\hline Elderly vs non-elderly & $2.66(0.55-12.51)$ & 0.209 \\
\hline \multicolumn{3}{|l|}{ Sex } \\
\hline Male vs female & $2.55(0.54-12.15)$ & 0.224 \\
\hline \multicolumn{3}{|l|}{ Feeding route } \\
\hline Oral vs enteral tube & $0.13(0.03-0.55)$ & 0.001 \\
\hline \multicolumn{3}{|l|}{ BMI } \\
\hline Normal vs other categories & $0.95(0.85-1.05)$ & 0.282 \\
\hline \multicolumn{3}{|l|}{ Reasons for admission } \\
\hline AKI/insufficiency vs none & $1.02(0.13-8.28)$ & 0.982 \\
\hline $\begin{array}{l}\text { Pneumonia/respiratory insufficiency } \\
\text { vs none }\end{array}$ & $0.42(0.05-3.35)$ & 0.397 \\
\hline UTI vs none & - & - \\
\hline Acute $\mathrm{Gl}$ disease vs none & - & - \\
\hline CVD vs none & - & - \\
\hline Metabolic derangement vs none & $1.33(0.16-10.85)$ & 0.787 \\
\hline CAD vs none & $3.21(0.65-15.77)$ & 0.130 \\
\hline HTN/heart failure vs none & $3.10(0.63-15.22)$ & 0.142 \\
\hline Skin infection vs none & - & - \\
\hline Neoplasm vs none & $4.02(1.10-14.67)$ & 0.023 \\
\hline Acute MS disease vs none & - & - \\
\hline Others vs none & - & - \\
\hline \multicolumn{3}{|l|}{ Co-morbidities } \\
\hline With vs without & $0.98(0.96-0.99)$ & 0.521 \\
\hline Cancer vs none & $1.76(0.49-6.34)$ & 0.383 \\
\hline Cardiovascular vs none & $1.55(0.33-7.42)$ & 0.578 \\
\hline Lung disease vs none & $0.82(0.10-6.64)$ & 0.855 \\
\hline Gastrointestinal vs none & $1.80(0.22-14.74)$ & 0.581 \\
\hline Kidney disease vs none & $1.80(0.51-6.33)$ & 0.350 \\
\hline Genitourinary vs none & - & - \\
\hline Endometabolic vs none & - & - \\
\hline Neurologic vs none & - & - \\
\hline Rheumatologic vs none & - & - \\
\hline Hematologic vs none & - & - \\
\hline Dermatologic vs none & - & - \\
\hline Total lymphocyte count & $1.00(1.00-1.00)$ & 0.298 \\
\hline Albumin & $0.37(0.17-0.81)$ & 0.013 \\
\hline $\mathrm{HbA1c}$ & $0.86(0.56-1.32)$ & 0.490 \\
\hline $\begin{array}{l}\text { Nutritional status } \\
\text { Severely-malnourished vs } \\
\text { moderately-malnourished }\end{array}$ & $14.35(1.80-114.49)$ & 0.001 \\
\hline
\end{tabular}

Table 5. Association between malnutrition and mortality

\begin{tabular}{lcc}
\hline Nutritional status & Adjusted Odds Ratio (Cl 95\%) & $\boldsymbol{p}$-value \\
\hline $\begin{array}{l}\text { Severely-malnourished vs } \\
\text { moderately-malnourished }\end{array}$ & $8.91(1.04-76.18)$ & 0.046 \\
\hline
\end{tabular}

however, only malnutrition was significantly associated with mortality. Those severely-malnourished had almost 9 times the odds of dying compared to moderatelymalnourished patients (Table 5).

\section{DISCUSSION}

A total of $83.8 \%$ of hospitalized patients with type 2 diabetes were malnourished in our study. This is much greater than previously reported prevalence rates of hospital malnutrition in general $(48-53 \%){ }^{6}$ This suggests that patients with type 2 diabetes have a higher prevalence of malnutrition in the hospital setting.

Most of the patients were elderly, and increasing age was associated with higher degrees of malnutrition. Elderly patients are at risk for malnutrition due to frailty, polypharmacy, general health decline including physical disability, dementia, cognitive decline, poor appetite, eating dependencies, dysphagia, delirium and constipation. ${ }^{11,12}$ Most of the patients admitted were male, however sex was not a significant factor for nutritional status. The most common reasons for admission were pneumonia/respiratory insufficiency, neoplasm, and acute gastrointestinal disease. Only neoplasm was associated with mortality but not length of stay. More than $96 \%$ of patients had co-morbidities, and cardiovascular disease was the most prevalent co-morbid condition. However, this did not significantly affect the nutritional status and hospital outcome.

In general, hyperglycemia on admission has been associated with poorer outcomes. ${ }^{13}$ In our study, however, glycemic control based on $\mathrm{HbA1c}$ showed that a lower value was observed with more severe malnutrition. More chronically ill patients such as those with debilitating diseases and cancer may have better glycemic control related to reduction in food intake, presence of liver and/or kidney dysfunction. Furthermore, factors affecting the level of hemoglobin such as anemia and renal insufficiency may have contributed to these findings. Therefore, our study suggests that admission $\mathrm{HbA} 1 \mathrm{c}$ may not be a robust predictor of mortality or length of stay in the face of malnutrition.

Among the different factors, age group, BMI category, feeding route, admission for metabolic derangement and neoplasm, presence of cancer and lung co-morbidities, albumin and $\mathrm{HbA} 1 \mathrm{c}$ were the confounders of nutritional status. However, in the univariate and multivariate analyses, in addition to malnutrition in the hospital setting (i.e., moderately-malnourished and severelymalnourished), only BMI significantly affected and was negatively correlated with LOS, while feeding route, admission for neoplasm, and low albumin levels were significantly associated with mortality.

Well-nourished patients had the highest mean BMI among the 3 groups. Moderately-malnourished patients had higher mean BMI than severely-malnourished patients. Higher BMI was associated with shorter LOS but not associated with mortality based on the results of the study. Patients with type 2 diabetes tended to be more overweight or obese at baseline. Chronically-ill patients may have experienced weight loss possibly due to poor intake or appetite, depression, hypercatabolic state, systemic inflammation, etc., hence lower BMI compared to patients with more acute conditions. This may have contributed to higher BMI seen among patients with diabetes, who had shorter LOS. Severe malnutrition was also associated with longer LOS.

All well-nourished patients were fed through oral route or by mouth. Feeding through enteral tube was only observed in the malnourished groups. Patients who were fed by enteral tube had higher odds of dying compared to patients who were fed by mouth. Based on their clinical profiles, patients who were on tube feeding were more likely to be chronically-ill and have co-morbidities, hence these patients tended to be malnourished, predisposing them to higher risk of poor hospital outcomes. Among the reasons for admission, neoplasm was associated with 4 times the odds of dying. Malignant neoplasms are known to be associated with depressed immune system, reduced appetite and hypercatabolism, which can significantly affect nutritional status. 
Higher levels of albumin were associated with reduced mortality in our study. Hypoalbuminemia has traditionally been seen as a marker for poor nutritional status. However, it is now posited rather to reflect an inflammatory state. ${ }^{14}$ Inflammation often results in hypercatabolism with increased protein and caloric requirements. Measuring albumin levels may be useful for diagnosing inflammation and assessing nutrition risk by identifying patients at risk for adverse outcomes if adequate nutrition is not administered..$^{15}$ As inflammation resolves, albumin levels increase and nutrition risk is thus reduced. We also confirmed that malnutrition in hospitalized type 2 diabetes was associated with mortality. No mortality was reported among well-nourished patients. Mortality rate was highest in the severely-malnourished group with almost 9 times the odds of dying than the moderately-malnourished group.

This study analyzed the association between $\mathrm{HbA1c}$ and other factors affecting nutritional status to hospital outcomes among patients with type 2 diabetes. Contrary to other published literature, we observed that TLC was not associated with poor nutritional status. We confirmed the results of other studies done in elderly patients (who comprise the majority of our study population) that have likewise failed to find a correlation between TLC and malnutrition. ${ }^{16}$ Our study was limited only to type 2 diabetes as we only had one case of type 1 diabetes among the eligible patients.

Type 1 and type 2 diabetes have different phenotypes in general, one of which is BMI. Patients with type 1 diabetes are generally not obese and patients with type 2 diabetes are generally overweight or obese. ${ }^{17,18}$ The type of diabetes may have an impact on the results of BMI and other parameters. Available data were also limited to include patients who had complete laboratory results. Since $\mathrm{HbA1c}$ is affected by multiple factors such as anemia, renal insufficiency, and those associated with red blood cell turnover, point-of-care testing for glucose could have provided more information but was not available. Since the study was limited to non-ICU patients (to remove the confounding factor of being critically-ill as a cause of poor outcome), mortality rate was expectedly lower.

We recommend a prospective multicenter study involving patients with type 1 and type 2 diabetes on the effects of age, sex, BMI categories, types of diabetes, glycemic control, and TLC on the nutritional status and outcomes of hospitalized patients. Although BMI is part of the nutrition risk assessment for patients at risk for malnutrition in the hospital setting, further studies on optimal BMI category/ range affecting hospital outcomes are recommended. Studies including other parameters indicating glycemic control such as point-of-care testing for glucose and continuous glucose monitoring are also suggested. We also recommended to study factors affecting the level of TLC, and the significance and consideration of this parameter on nutritional risk assessment in persons with diabetes.

\section{CONCLUSION}

Malnutrition is highly prevalent among hospitalized adult patients with type 2 diabetes. Lower BMI categories and severe malnutrition were associated with greater LOS. Severely-malnourished patients had longer LOS compared to well-nourished patients by an average of 2.2 days. Mortality was observed only in malnourished patients. Artificial feeding route, admission for neoplasm, lower albumin levels, and malnutrition were associated with mortality. Lower $\mathrm{HbA1c}$ levels were seen in malnourished patients, but did not correlate with length of stay or mortality. Greater degrees of malnutrition were associated with higher mortality.

\section{Acknowledgments}

The authors would like to thank their institution for its support, and for providing them their biostatisticians, Maria Joy Taneo and Macario Reandelar Jr., MD, MSPH, FPAFP, who have greatly helped and contributed in the statistical analyses of their research data.

\section{Statement of Authorship}

All authors certified fulfillment of ICMJE authorship criteria.

\section{Author Disclosure}

The authors declared no conflicts of interest.

\section{Funding Source}

None.

\section{References}

1. World Health Organization. Fact sheets. Malnutrition. https://www. who.int/news-room/fact-sheets/detail/malnutrition

2. Cederholm $\mathrm{T}$, Barazzoni $\mathrm{R}$, Austin $\mathrm{P}$, et al. ESPEN guidelines on definitions and terminology of clinical nutrition. Clin Nutr. 2017;36(1):49-64. PMID: 27642056. https://doi.org/10.1016/j. clnu.2016.09.004

3. Tappenden KA, Quatrara B, Parkhurst ML, Malone AM, Fanjiang G, Ziegler TR. Critical role of nutrition in improving quality of care: An interdisciplinary call to action to address adult hospital malnutrition. J Acad Nutr Diet. 2013;113(9):1219-37. PMID: 23871528. https://doi. org/10.1016/j.jand.2013.05.015.

4. Mc Whirter JP, Pennington CR. Incidence and recognition of malnutrition in hospital. Br Med J. 1994;308(6934):945-8. PMID: 8173401. PMCID: PMC2539799. https://doi.org/10.1136/bmj.308.6934.945.

5. Baccaro F, Moreno JB, Borlenghi C, et al. Subjective global assessment in the clinical setting. JPEN J Parenteral Enteral Nutr. 2007;31(5):406-9. PMID: 17712149. https://doi.org/10.1177/0148607107031005406.

6. Hospital Malnutrition and Clinical Nutrition Program Task Force Metro Manila, Philippines. The value of implementing a clinical nutrition program and nutrition support team (NST) to address the problem of malnutrition in the hospitals of the Philippines. PhilSPEN Online Journal of Parenteral and Enteral Nutrition. Jan 2010 - Jan 2012:Article 5(POJ_0017):42-54. http://www.philspenonlinejournal. com/POJ 0017.html

7. Cabangon MR, Narvacan-Montano C, del Rosario-Capellan ML, Campos-Cagingin ML. Prevalence of malnutrition among patients with diabetes mellitus type 2 admitted in a tertiary hospital. Philipp J Intern Med. 2016;54(2):1-11. https://drive.google.com/file/ d/1InkHyJj70wc1P_ouCS72FPDPNrUTYI2R/view.

8. Barker LA, Gout BS, Crowe TC. Hospital malnutrition: Prevalence, identification and impact on patients and the healthcare system. Int J Environ Res Public Health. 2011;8(2):514-27. PMID: 21556200. PMCID: PMC3084475. https://doi.org/10.3390/ijerph8020514.

9. Dominguez RJ. Burden of malnutrition in a tertiary care hospital in Baguio City. SAGE Pub. 2013:1-7. https://doi. org/10.1177/2158244013504936.

10. Alberda C, Gramlich L, Jones N, at al. The relationship between nutritional intake and clinical outcomes in critically ill patients: Results of an international multicenter observational study. Intensive Care Med. 2009;35(10):1728-37. PMID: 19572118. https://doi.org/10.1007/ s00134-009-1567-4.

11. Favaro-Moreira NC, Krausch-Hofmann S, Matthys C, et al. Risk factors for malnutrition in older adults: A systematic review of the literature based on longitudinal data. Adv Nutr 2016;7(3):507-22 . PMID: 27184278. PMCID: PMC4863272. https://doi.org/10.3945/ an.115.011254

12. Avelino-Silva TJ, Jaluul O. Malnutrition in hospitalized older patients: Management strategies to improve patient care and clinical outcomes. Int J Gerontol. 2017;11(2):56-61. https://reader.elsevier. $\mathrm{com} / \mathrm{reader} / \mathrm{sd} / \mathrm{pii} / \mathrm{S} 1873959817301461$ ?token=9B6206B33C4F64B3 021175C7BD4102AB18C5E0C81B2E5555294A3CA4499D6FA141E6 66BE650C194DDD6687E0CEC6FF12\&originRegion=eu-west-1\&originCreation $=20210815062934$. 
13. Umpierrez GE, Isaacs SD, Bazargan N, You X, Thaler LM, Kitabchi AE. Hyperglycemia: An independent marker of in-hospital mortality in patients with undiagnosed diabetes. J Clin Endocrinol Metab. 87(3):978-82. PMID: 11889147. https://doi.org/10.1210/jcem.87.3.8341.

14. Evans DC Corkins MR, Malone A, et al. The use of visceral protein as nutrition markers: An ASPEN position paper. Nutr Clin Pract. 2021;36(1):22-8. PMID: 33125793. https://doi.org/10.1002/ncp.10588.

15. Demling RH. Nutrition, anabolism, and wound healing process: An overview. Eplasty. 2009;9:e9. PMID: 19274069. PMCID: PMC2642618.

16. Kuzuya M, Kanda S, Koike T, Suzuki Y, Iguchi A. Lack of correlation between total lymphocyte count and nutritional status in the elderly. Clin Nutr. 2005;24(3):427-32. PMID: 15896430. https://doi.org/10.1016/j. clnu.2005.01.003.
17. American Diabetes Association. Diagnosis and classification of diabetes mellitus. Diabetes Care. 2007;30(Suppl 1):S42-7. PMID: 17192378. https://doi.org/10.2337/dc07-S042.

18. Al-Goblan AS, Al-Alfi MA, Khan MZ. Mechanism linking diabetes mellitus and obesity. Diabetes Metab Syndr Obes. 2014.7:587-91. PMID: 25506234. PMCID: PMC4259868. https://doi.org/10.2147/ DMSO.S67400

Authors are required to accomplish, sign and submit scanned copies of the JAFES Author Form consisting of: (1) Authorship Certification, that authors contributed substantially to the work, that the manuscript has been read and approved by all authors, and that the requirements for authorship have been met by each author; (2) the Author Declaration, that the article represents original material that is not being considered for publication or has not been published or accepted for publication elsewhere, that the article does not infringe or violate any copyrights or intellectual property rights, and that no references have been made to predatory/suspected predatory journals; (3) the Author Contribution Disclosure, which lists the specific contributions of authors; (4) the Author Publishing Agreement which retains author copvright, grants publishing and distribution rights to JAFES, and allows JAFES to apply and enforce an Attribution-Non-Commercial Creative Commons user license; and (5) the Conversion to Visual Abstracts ( ${ }^{*}$ optional for original articles only) to improve dissemination to practitioners and lav readers Authors are also required to accomplish, sign, and submit the signed ICMJE form for Disclosure of Potential Conflicts of Interest. For original articles, authors are required to submit a scanned copy of the Ethics Review Approval of their research as well as registration in trial registries as appropriate. For manuscripts reporting data from studies involving animals, authors are required to submit a scanned copy of the Institutional Animal Care and Use Committee approval. For Case Reports or Series, and Images in Endocrinology, consent forms, are required for the publication of information about patients; otherwise, appropriate ethical clearance has been obtained from the institutional review board. Articles and any other material published in the JAFES represent the work of the author(s) and should not be construed to reflect the opinions of the Editors or the Publisher.
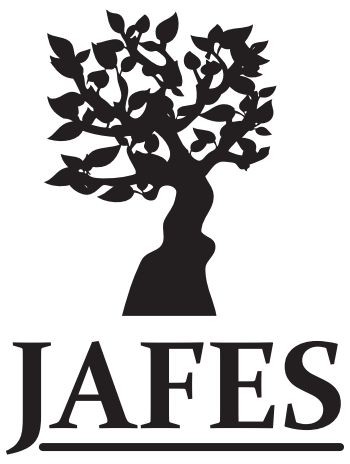

\section{Unique, interesting, enlightening. Your case report and the JAFES.}




\section{APPENDIX}

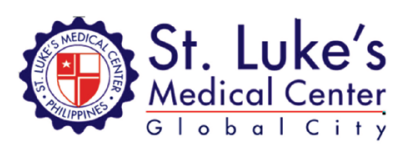

CLINICAL NUTRITION SERVICES

NUTRITIONAL ASSESSMENT AND RISK LEVEL FORM (ADULT)

\begin{tabular}{|l|l|l|l|l|}
\hline Date Admitted & \multicolumn{2}{l|}{ Room / Bed No. } & File No. & PIN \\
\hline Patient's Name (Last, First, Middle Name) & BMI & Age \\
\hline Height (m) & Weight (kg) & & \\
\hline Attending Physician & Diagnosis & \\
\hline
\end{tabular}

\begin{tabular}{|c|c|c|c|}
\hline Criteria & Normal / Mild & Moderate & Severe \\
\hline Weight Loss & none & $<10 \%$ of usual weight & $>10 \%$ of usual weight \\
\hline Food Intake (last 1-2 months) & no change & suboptimal & starvation \\
\hline Gastro symptoms (>2 weeks) & none & nausea, vomiting & anorexia, diarrhea severe \\
\hline Functional Capacity & no change & $\begin{array}{c}\text { dysfunction }<3 \text { weeks } \\
\text { suboptimal work } \\
\text { bedridden }<2 \text { weeks }\end{array}$ & bedridden $>2$ weeks \\
\hline $\begin{array}{l}\text { Disease and relation to } \\
\text { nutritional requirements }\end{array}$ & no or low stress & moderate stress & severe stress \\
\hline Physical Examination & $\begin{array}{l}0 \text { subcutaneous fat } \\
\text { and/or muscle loss }\end{array}$ & $\begin{array}{l}+1 \text { to } 2 \text { subcutaneous fat } \\
\text { and/or muscle loss }\end{array}$ & $\begin{array}{l}+3 \text { subcutaneous fat } \\
\text { and/or muscle loss }\end{array}$ \\
\hline Edema / Ascites & none & none & +1 or +2 \\
\hline
\end{tabular}

\begin{tabular}{|c|c|c|c|c|c|c|}
\hline SGA Grade & A & 0 & $\mathrm{~B}$ & 1 & $\mathrm{C}$ & 3 \\
\hline BMI & $18.5-24.9$ & 0 & $25-29.9$ & 1 & $<18.5$ or $\geq 30$ & 2 \\
\hline Albumin g/dL & $>3.4$ & 0 & $2.5-3.4$ & 1 & $<2.5$ & 2 \\
\hline TLC & $\geq 1500$ & 0 & 900 but $<1500$ & 1 & $<900$ & 2 \\
\hline
\end{tabular}

\begin{tabular}{|c|ccc|c|}
\hline \multicolumn{4}{|c|}{ TOTAL SCORE } & \multicolumn{4}{c|}{ NURITION RISK LEVEL } & NUTRITIONAL STATUS \\
\hline & 0 & $\square$ Level 1 & LOW RISK & Normal \\
& $1-2$ & $\square$ Level 2 & MODERATE RISK & $\square$ Moderate malnutrition \\
& $\geq 3$ & $\square$ Level 3 & HIGH RISK & Severe malnutrition \\
\hline
\end{tabular}

\begin{tabular}{|ll|}
\hline Assessed by: & \\
\cline { 2 - 3 } & $\begin{array}{l}\text { REGISTERED DIETITIAN } \\
\text { (Signature over Name Stamp) }\end{array}$ \\
\hline
\end{tabular}

